\title{
CRÍTICA Y VANGUARDIA EN EL ARTE ESPAÑOL DE LOS CINCUENTA: LA CORRESPONDENCIA ENTRE GAYA NUÑO Y MANOLO MILLARES
}

\author{
José Luis DE LA Nuez SANTANA \\ Universidad Carlos III de Madrid
}

\begin{abstract}
En este texto se estudian los contenidos de la correspondencia mantenida entre el crítico e historiador del arte Juan Antonio Gaya Nuño y el pintor Manolo Millares en el contexto español de la primera mitad de los cincuenta del siglo pasado. A través de este análisis se revelan aspectos fundamentales del pensamiento artístico de los autores de la correspondencia, así como también sus valoraciones del ambiente artístico de este periodo y la labor que ambos desempeñan como editores de libros de arte. Estos documentos son también de gran interés para conocer la actividad de Millares como impulsor del arte vanguardista en Canarias, y nos permiten reconocer las dificultades del artista para da a conocer su pintura más allá de las fronteras insulares.
\end{abstract}

Palabras clave: Juan Antonio Gaya Nuño; Manolo Millares; Crítica artística; Historia del arte; Pintura; Posguerra española; Eugenio d'Ors; Abstracción; Picasso; Giovanni Papini; Dalí; Gaudí; Surrealismo; Galerías de arte.

\section{ART CRITICISM AND VANGUARD IN SPANISH ART OF THE 1950s: THE CORRESPONDENCE BETWEEN GAYA NUÑO \& MANOLO MILLARES}

This article explores the contents of the correspondence between the critic and art historian Juan Antonio Gaya Nuño and the painter Manolo Millares in the context of the Spain of the first half of 1950s. Through this analysis fundamental aspects of the artistic thought of both are revealed, as well as their assessment of the artistic life of this period and the work they carried out as art book editors. These documents are likewise of great interest for learning about Millares' efforts to promote avant-garde art in the Canaries and conversely, his difficulties in promoting his own painting beyond the islands.

Key words: Juan Antonio Gaya Nuño; Manolo Millares; Art criticism; Art History; Painting; Spanish postwar period; Eugenio d'Ors; Abstraction; Picasso; Giovanni Papini; Dalí; Gaudí; Surrealism; Art galleries.

Durante la primera mitad de los cincuenta, el crítico Juan Antonio Gaya Nuño y el artista Manolo Millares mantienen una correspondencia bastante regular, como se deduce de la confrontación de la documentación existente a este respecto en la Fundación Gaya Nuño de Soria y en 
el archivo de Elvireta Escobio (viuda de Manolo Millares) de Cuenca. Todo este intercambio epistolar ofrece una interesante información, tanto sobre las actividades desempeñadas por el crítico y el pintor como sobre el mundo artístico español del momento. Como sucede frecuentemente en este tipo de documentos, en las cartas se entremezclan las noticias relativas al mundo profesional con otras que atienden más bien a lo personal, muy oportunas para la reconstrucción biográfica de los protagonistas. Las posiciones del crítico y del artista en esos años no eran equiparables, con independencia de que se dedicaran a actividades distintas en el mundo del arte. Esto se explica sobre todo por la diferencia de edad, así como por el grado de influencia de cada uno de ellos en sus respectivos ámbitos, más importante en el caso de Gaya Nuño, como bien deja notar en sus cartas Millares, que se dirige al crítico manifestando siempre un reconocimiento de su valía y autoridad intelectual. En todo caso, les unen intereses comunes y eso explica en gran medida la existencia de esta correspondencia. Como se puede leer en uno de los cuadernos de la colección "Planas de poesía"1, Millares incluyó a Gaya Nuño en el grupo de los "amigos sin rostro", formado por artistas y críticos de la Península con los que se carteaba. La correspondencia mantenida con los críticos ${ }^{2}$ en esos años, insistente y bien orientada, supuso para el artista canario la posibilidad de dar a conocer y valorar su obra en unos momentos claves en su trayectoria como creador, cuando su pintura se afirma en una dirección claramente vanguardista.

\section{Dos trayectorias profesionales}

Si bien es verdad que Gaya Nuño desempeñó una interesante labor como gestor cultural cuando se encargó de la dirección de las Galerías Layetanas de Barcelona por encargo de José Gudiol entre 1947 y 1951, lo cierto es que la actividad principal del autor soriano en el lustro que abarca esta correspondencia está relacionada, como no podía ser de otra forma, con la crítica y la historia del arte. Su labor en este terreno es impresionante ${ }^{3}$. Fueron muchísimos los periódicos y revistas en las que colaboró como $\mathrm{crítico}^{4}$, colaboraciones muchas de ellas iniciadas en este periodo o en la década anterior, como sucede con Ínsula, Revista de Ideas Estéticas, Correo Literario, Clavileño, Cuadernos Hispanoamericanos y La Estafeta Literaria, entre otras. También escribió en distintos periódicos, como $A B C$, El Universal de Caracas y Diario de Barcelona, aunque para este último habrá que esperar a la década de los sesenta. La posición crítica de Gaya Nuño en estos años está claramente definida por una decantación hacia el arte de vanguardia, si bien desde una postura claramente independiente y llena de matices. Son reveladoras en este sentido las opiniones despectivas sobre el surrealismo que vierte en su libro La Pintura ${ }^{5}$

\footnotetext{
1 Vid. Millares, Manolo y Azcoaga, Enrique, "El hombre de la pipa. 11 dibujos”, Planas de Poesía, XIII, 5 de febrero de 1951, s/p.

${ }^{2}$ Fundamentalmente, Enrique Azcoaga, Sebastián Gasch, Rafael Santos Torroella, Cesáreo Rodríguez Aguilera y Eduardo Westerdahl. Con mucho, la más importante fue la correspondencia mantenida con este último, tanto por los contenidos como por el número de cartas, que superan el centenar. Ya en Madrid, Millares mantendrá correspondencia abundante con Juan Eduardo Cirlot y Vicente Aguilera Cerni, sin olvidar, en la década siguiente, a extranjeros, como los italianos Enrico Crispolti y Lea Vergine, así como la francesa Françoise Choay.

3 Sobre la contribución de Gaya Nuño a la historia del arte y la crítica, vid. Borrás, Gonzalo M., "Gaya Nuño, historiador y crítico de arte", en AA.VV., Catálogo del legado pictórico de Juan Antonio Gaya Nuño, Caja Salamanca y Soria, Soria, 1994, pp. 29-43.

${ }^{4}$ Toda la producción bibliográfica de Juan Antonio Gaya Nuño como crítico e historiador del arte aparece recogida en su integridad en Martínez LaiseCA, José María, Gaya Nuño y su tiempo: Literatura y Arte, Junta de Castilla y León, 1987.

5 Gaya NuÑo, Juan A., La Pintura, Ediciones Pegaso, Madrid, 1955.
} 
o en su artículo "Claves íntimas de la crítica de arte" logía crítica. Desde luego, como sucedía con muchos críticos del momento, su pensamiento artístico estaba muy influido por el formalismo de Eugenio d'Ors, en quien vio siempre un referente inexcusable, a pesar de sus veleidades políticas, que él quiso disculpar, como se puede constatar en el estudio que dedica al catalán en su Historia de la Crítica de Arte en España ${ }^{7}$. De hecho, Gaya Nuño fue miembro de la dorsiana Academia Breve de Crítica de Arte. Por otra parte, su participación en los debates suscitados en eventos importantes que afectan al arte español del momento, como las Bienales Hispanoamericanas celebradas en España (1951 y 1955) o el Congreso de Arte Abstracto de Santander $(1953)^{8}$, da una idea de su protagonismo en el campo de la crítica española de posguerra. A la vez, Gaya desarrollaba también una labor más que estimable como historiador del arte. Llama la atención la amplitud de su campo de estudio, pues no solamente se interesó por el arte medieval, renacentista y barroco, sino también por el contemporáneo. Gaya dio a conocer sus estudios histórico-artísticos también en revistas especializadas, como el Boletín de la Sociedad Española de excursiones, Goya o el Archivo Español de Arte, así como en numerosas monografías, algunas de las cuales aparecen en estos años y son citadas en la correspondencia, como ocurre con su Picasso, de 1950. La importancia que Gaya Nuño le concedía a la historia del arte no era ajena a la que podía conceder a la crítica, pues, de hecho, siguiendo los planteamientos de Lionello Venturi, entendía la historia de la crítica identificada con la historia del arte, como se puede constatar en su ya citada Historia de la Crítica de Arte en España.

En el caso de Manolo Millares ${ }^{9}$, el lustro que llama nuestra atención es el de su afirmación como artista vanguardista en Las Palmas, donde está implicado en dos empresas editoriales importantes: la de la colección poética "Planas de Poesía"10 que lleva con sus hermanos Agustín y José María, y la de la colección de monografías de artistas llamada "Los arqueros"11, que dirigió hasta su último número, publicado en 1954. Millares tuvo además un papel destacado en la formación e impulso del grupo grancanario "LADAC" ("Los Arqueros del Arte Contemporáneo") ${ }^{12}$. En el terreno de lo estrictamente plástico, estos años responden a un momento de asimilación y variedad de planteamientos pictóricos. En el primer Millares se ven influencias tan variadas como

${ }^{6}$ Gaya Nuño, Juan A., "Claves íntimas sobre la crítica de arte”, Cuadernos Hispanoamericanos, n. ${ }^{o}$ 125, mayo de 1960, pp. 165-181.

7 Vid. Gaya Nuño, Juan A., Historia de la Crítica de Arte en España, Madrid, Ibérico Europeo de Ediciones, 1976, pp. 253-272.

${ }^{8}$ Fue este evento, precisamente, el que permitió que se vieran por primera vez Juan Antonio Gaya Nuño y Manolo Millares. Éste participó en la "I Exposición Internacional de Arte Abstracto" con tres pictografías, mientras que el primero intervino como conferenciante.

${ }^{9}$ La bibliografía existente sobre la obra del pintor grancanario es muy densa, aunque algunos títulos son referencias ineludibles. Destacamos entre éstas la monografía que le dedicó José Augusto França (Millares, Barcelona, Polígrafa, 1979), así como los distintos trabajos realizados por Juan Manuel Bonet (puede destacarse el catálogo Millares, Madrid, Museo Nacional Centro de Arte Reina Sofía, 1992) y, más recientemente los de Alfonso de la Torre, responsable del catálogo razonado de la obra del artista (Manolo Millares: Pinturas. Catálogo razonado, Madrid, Museo Nacional Centro de Arte Reina Sofía, Fundación Azcona, 2004).

${ }^{10}$ Existe edición facsímile de estos cuadernos hecha por el Gobierno de Canarias (2 volúmenes, 1994) y dirigida por Jesús Páez.

${ }^{11}$ Reproducción facsímile de estas monografías acompañan la obra de CARREÑo Corbella, Pilar, LADAC: El sueño de los arqueros, Viceconsejería de Cultura y Deportes, Gobierno de Canarias, 1990.

12 Grupo grancanario formado por los pintores Alberto I. Manrique, Juan Ismael, Manolo Millares, José Julio Rodríguez, Elvireta Escobio y Felo Monzón. La historia del grupo se inicia con la exposición celebrada en el Museo Canario de Las Palmas en enero de 1950 y concluye con otra en el mismo local, que se inauguró en junio de 1952. Las intenciones del grupo se dieron a conocer en un manifiesto con ocasión de su exposición en el Club de Universitarios de Las Palmas a finales de 1950. Sobre la historia de este grupo, vid. el citado libro de Pilar Carreño Corbella.

Arch. esp. arte, LXXXIV, 334, ABRIL-JUNIO 2011, 107-124, ISSN: 0004-0428 
pueden ser las de Dalí, Van Gogh, Barradas y Torres García. Desde luego, lo más destacado es la aparición de sus "pictografías", serie caracterizada por una recreación abstracta de los signos aborígenes canarios, con influencias de Miró y Paul Klee. En los últimos años de esta etapa hay una clara inclinación por el uso de nuevos materiales, en sintonía con su aproximación al informalismo, con el que se identificará ya en sus primeros años madrileños de manera total. Preocupado por dar a conocer su obra más allá de las fronteras insulares, durante estos años expuso en varias ocasiones tanto en Barcelona como en Madrid. Por este motivo, algunas salas importantes de la época, como la galería Jardín de Barcelona o las salas Clan y Buchholz ${ }^{13}$ de Madrid, aparecen citadas en esta correspondencia.

\section{LA CORRESPONDENCIA}

\section{La actividad plural de Gaya Nuño a través de las cartas}

La correspondencia entre el crítico y el pintor consta de un total de 84 cartas, de las que Gaya escribió 40 y el resto el pintor canario. Abre la correspondencia una carta de Millares fechada el 29 de mayo de 1950 y la cierra otra del 22 de julio de 1955, también escrita por éste, pocos meses antes de que abandonara Las Palmas y estableciera su residencia en Madrid. Por lo que atañe a las cartas escritas por Gaya Nuño, las doce primeras están fechadas en Barcelona y las siguientes en Madrid.

De los contenidos que se pueden extraer de las cartas escritas por el autor soriano se deduce la existencia de temas reiterados, como el que se refiere a su labor como director de las Galerías Layetanas o el de su actividad como editor de libros de arte, pero también se comentan asuntos relacionados con el ambiente artístico nacional. Asimismo, Gaya se interesó por las actividades emprendidas por Millares, así como por su obra, y son de gran interés sus comentarios a este respecto. En ocasiones, además se nos revela el penoso pasado del crítico, represaliado político que había sido encarcelado después de la Guerra Civil en distintas prisiones, entre ellas la de Las Palmas.

Cuando Millares contacta por primera vez con el crítico soriano, éste dirige las Galerías Layetanas (incluso sus cartas llevan el membrete de esta sala). Como ya se adelantó, Gaya abandonará la dirección de esta sala en 1951, lo que supuso dejar su residencia en Barcelona y trasladarse de manera definitiva a Madrid. Las razones por las que tomó esta decisión están expuestas de manera bastante clara en dos de las cartas que escribe al pintor. Casualmente, ninguna de las dos está fechada, pero corresponden con seguridad a los primeros meses de 1952. En la primera de ellas, Gaya le comunica al pintor que ha decidido abandonar Barcelona y cesar en su responsabilidades con las Galerías Layetanas porque "éstas van a comenzar una etapa de pintura pompier y mansa, y yo, pobrísimo, soy demasiado millonario y señor para prestarme a ello"14. Los motivos de su ruptura con la galería tienen que ver, por tanto, con una disparidad de criterios $\operatorname{artísticos}^{15}$, aunque a juzgar por los comentarios que se pueden entresacar de esta correspondencia, muy a gusto no estaba en Barcelona. Hay en este episodio, por otro lado, muestras más que

13 A propósito de estas galerías y el arte madrileño en los cincuenta, vid. AA.VV., Del Surrealismo al Informalismo. Arte de los años 50 en Madrid, Comunidad de Madrid, 1991.

${ }^{14}$ Gaya NuÑo, Juan A., "Carta personal dirigida a Manolo Millares”, Barcelona, [enero de 1952] (Archivo Elvireta Escobio, Cuenca).

15 Gonzalo Borrás, en su estudio ya citado, explica el fin de la colaboración de Gaya con Gudiol porque éste "planeaba enterrar las Galerías Layetanas para sustituirlas por una empresa editorial". BorRÁs, Gonzalo M., op. cit., p. 39. 


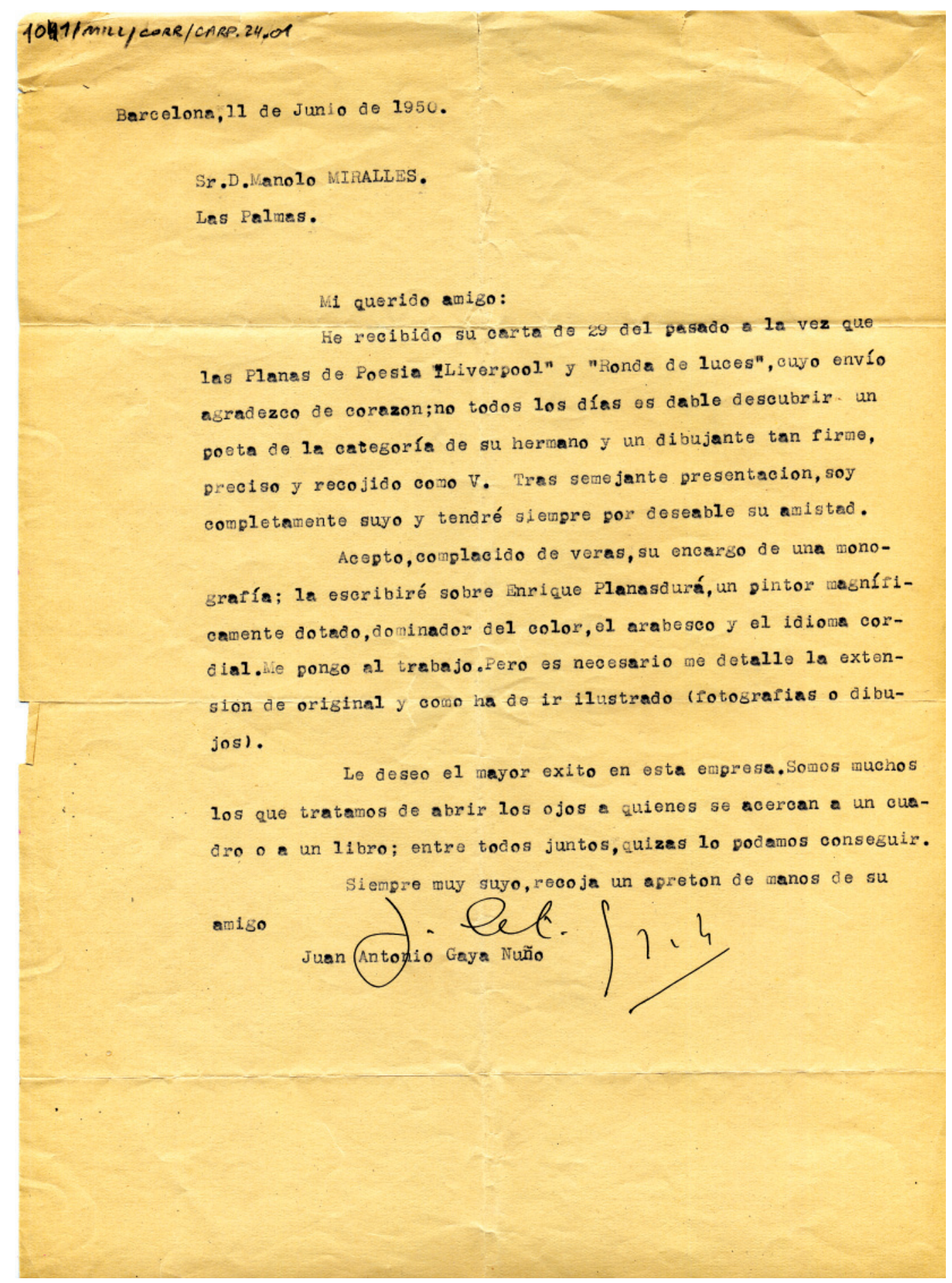

Fig. 1. Carta de Gaya Nuño (11 de junio de 1950).

Arch. esp. arte, LXXXIV, 334, ABRIL-JUNIO 2011, 107-124, ISSN: 0004-0428 
elocuentes del espíritu independiente que animó siempre el trabajo de Gaya Nuño, poco proclive a los acuerdos de conveniencia y a la condescendencia que acompañó a tantos críticos españoles de la época. En la segunda carta, la primera que escribe ya desde Madrid, es más explícito sobre las causas de su decisión. Con manifiesto desagrado, le comenta al pintor: "En Barcelona he salido con el pelo blanco de disgustos. No es posible hacer lo que yo estaba haciendo allí; cuando se me propuso dirigir 'Galerías Layetanas' fue con carta blanca para hacer lo que se me antojase dentro de un mínimo sentido comercial; pero el capital se cansó enseguida y me querían hacer tragar arte lánguido y vendible. Renuncio, con todo y ser halagüeña la situación económica, y aquí me tiene"16.

La llegada de Gaya a Barcelona coincide con un resurgir de la vanguardia artística en la capital catalana, pues es ahora cuando se inician las actividades del grupo de "Dau al Set" y se llevan a cabo iniciativas expositivas con una clara orientación aperturista, como son las de "El Ciclo Experimental de Arte Nuevo" de la galería Jardín (1948-1951), y los "Salones de Octubre" (1948-1957), celebrados anualmente en las Galerías Layetanas, aunque ninguna responsabilidad tuviera nuestro crítico en su organización. No quiere todo esto decir que el arte adocenado y académico hubiera desaparecido del escenario catalán; de hecho, durante los años cuarenta se había manifestado un auge notable de un arte de ínfima calidad ligado con la especulación estraperlista $^{17}$. En general, los comentarios de Gaya Nuño a propósito del ambiente artístico catalán que se pueden leer en las cartas a su partida de Barcelona, especialmente sobre determinados críticos y artistas, dan a entender hasta qué punto el soriano no vivió su estancia catalana con mucha empatía. Los críticos y algunos de los pintores que aparecen citados mantenían a su vez contacto epistolar con Millares. Así sucede con los críticos Sebastián Gasch y Rafael Santos Torroella, pero también con el pintor Planasdurà, sobre el que Gaya editó una monografía para la colección "Los Arqueros"18. Éste y otro de los citados, Santi Surós, formó parte del grupo "Lais", que expondrá en el Museo Canario de Las Palmas en 1951, invitados por el grancanario "LADAC". Además, los tres artistas citados expondrán dibujos suyos en la colectiva "El dibujo en la joven pintura española", celebrada en el Club de Universitarios de Las Palmas en 1953 y organizada por Millares. Las opiniones que vierte Gaya Nuño sobre estos artistas y críticos son muy despreciativas, si se exceptúa el caso de Sebastián Gasch, "excelente persona a quien la vida no ha tratado muy bien. Sin embargo, ello no le ha hecho criar hiel ni mala intención. Conserva un entusiasmo muy juvenil por las cosas" "19. No opinaba de igual forma de Rafael Santos Torroella, sobre el que, le advierte a Millares, "le podría contar cosas en tal cantidad y saber que es preferible no intentarlo siquiera. Además esta cuartilla está bastante limpia y sería lástima ensuciarla" ${ }^{20}$. Poco amigables son también sus comentarios sobre el pintor Santi Surós, "que trata de ser celebridad gracias a su dinero y que ha desprestigiado a su comentarista [Sebastián Gasch] con el slogan de que 'a los críticos se les compra con una cena"'21. Tampoco queda muy bien parado en este ajuste de cuentas con el arte catalán que Gaya Nuño lleva a cabo en los últimos meses de su estancia en Barcelona, Hurtuna, "pintor mediocre, de personalidad oscura, tortuoso

\footnotetext{
16 Gaya Nuño, Juan A., "Carta personal dirigida a Manolo Millares”, Barcelona, [febrero de 1952] (Archivo Elvireta Escobio, Cuenca).

17 Sobre el arte catalán de estos años sigue siendo una lectura recomendable el libro de CIRICI PeLlicer, Alexandre, L'art catalá contemporani, Edición 62, Barcelona, 1970.

18 Gaya NuÑo, Juan A., Plasnadurà, Cuadernos de arte Los Arqueros, 1951.

19 Gaya NuÑo, Juan A., "Carta personal dirigida a Manolo Millares", Barcelona, 4 de diciembre de 1951 (Archivo Elvireta Escobio, Cuenca).

${ }^{20}$ Ibidem.

${ }^{21}$ Gaya Nuño, Juan A., "Carta personal dirigida a Manolo Millares”, Barcelona, 6 de septiembre de 1951 (Archivo Elvireta Escobio, Cuenca).
} 
y poco digno de confianza"22. No deben entenderse, en todo caso, estos comentarios, muy propios de la naturaleza un tanto irascible del crítico, como una descalificación general de todo el arte catalán. A la valoración entrañable que hace de Gasch habría que unir su interés y aprecio por determinados artistas que se manifiesta en monografías como las dedicadas a Ramón Rogent y Capdevila, publicadas durante estos años.

Efectivamente, hay mucho en esta correspondencia sobre la actividad de Gaya Nuño como editor y autor de libros de arte y colaborador en revistas culturales de prestigio. Leyendo estas cartas se deduce la existencia de una actividad notoria en este campo, y esto afecta tanto a los años pasados en Cataluña como a su etapa madrileña aquí recogida, aunque es sabido que fue a partir de su estadía en Barcelona cuando realmente el interés por el arte contemporáneo se volvió preponderante en su producción crítica. En la carta que marca el inicio de su correspondencia con el crítico, Millares se refiere con elogios a su Picasso $^{23}$, publicado ese mismo año, pero son sobre todo las monografías de la colección "El caballete vivo", de ediciones Sagitario (MadridBarcelona), las que salen a colación en más de una ocasión en estos documentos ${ }^{24}$. De esta colección salieron cinco libros, dos de ellos, los dedicados a Ramón Rogent y Francisco Cossío, fueron escritos por el propio Gaya, mientras que los siguientes, también citados en las cartas, el de Capdevila, Francisco Mateos y Mercadé, fueron escritos por Juan Eduardo Cirlot, Adriano del Valle y Sebastián Gasch, respectivamente; todos editados en 1951, salvo el último citado, que lo fue el año siguiente ${ }^{25}$. En la correspondencia del año 1952 se habla también de un libro de Gaya sobre pintura española actual, que no es otro que el titulado La pintura española del medio si$g l o^{26}$, un libro importante que, sin embargo, es comentado por el autor con su habitual despreocupación hacia las opiniones negativas que la obra pudiera suscitar en determinados círculos, sobre todo entre aquellos artistas que no aparecían citados. "Yo sé que el libro es arbitrario y partidista, pero estoy contento de que así sea. Y estoy contento de que V. esté contento"27, le comentaba a un Millares que había mostrado su agradecimiento por figurar entre los artistas seleccionados ${ }^{28}$. En el mes de marzo de ese mismo año, el crítico le escribe al pintor que se ha hecho cargo de la página de arte de la revista Ínsula, una responsabilidad que adquiría casi al mismo tiempo que llegaba a sus manos el artículo de Alberto Sartoris dedicado al artista canario $^{29}$, ciertamente, el primer artículo escrito en una revista de alcance nacional que se escribía sobre su pintura. Por lo demás, las colaboraciones de Gaya en esta prestigiosa revista literaria se prolongaron hasta el año de su muerte, en 1976, aunque se hicieron poco frecuentes a partir de $1959^{30}$. En la correspondencia que nos ocupa hay aún dos referencias más a artículos suyos en Ínsula, ambos no exentos de polémica, como correspondía a la personalidad libérrima de este

22 GaYa Nuño, Juan A., Doc. cit.

23 Gaya Nuño, Juan A., Picasso, Ediciones Omega, Barcelona, 1950.

24 Vid. Gaya Nuño, Juan A., "Cartas personales dirigidas a Manolo Millares", 29 de marzo, 20 de abril y 4 de diciembre de 1951 (Archivo Elvireta Escobio, Cuenca).

25 En la carta del 2 de enero de 1952, Gaya le comunica a Millares que su nombre figuraba entre los seleccionados para salir en esa colección de monografías, lo que luego no tuvo ninguna consecuencia, pues la colección se cerró ese mismo año.

26 GAYA NuÑo, Juan A., La pintura española del medio siglo, Omega, Barcelona, 1952.

27 Gaya NuÑo, Juan A., "Carta personal dirigida a Manolo Millares”, Barcelona, 22 de octubre de 1952 (Archivo Elvireta Escobio, Cuenca).

28 Se trata en realidad de la primera mención a la pintura de Millares en un libro dedicado al arte español contemporáneo: "En Las Palmas, Manolo Millares alterna las pictografías africanas de su raza con un gratísimo y titilante vibracionismo, granado cuidadosamente sutil”. GAYA Nuño, Juan A., La pintura española..., op. cit., p. 67.

29 SARTORIS, Alberto, "Manolo Millares: pictógrafo canario”, Ínsula, n. " 76, abril de 1952.

30 Gaya Nuño dejó de colaborar de manera regular en Ínsula en 1959, como consecuencia de la polémica desatada por un artículo de Julián Marías ("Consignas convergentes").

Arch. esp. arte, LXXXIV, 334, ABRIL-JUNIO 2011, 107-124, ISSN: 0004-0428 
autor. El primero de ellos, dedicado a Dali ${ }^{31}$, es citado de manera apresurada, aunque no deja de subrayar la contundencia con la que trata al pintor surrealista ${ }^{32}$. Tampoco fue muy favorable el artículo centrado en la obra del arquitecto Gaudí3 ${ }^{33}$. La polémica recepción de este texto ${ }^{34}$ es comentada por el autor en una carta de octubre del mismo año en los siguientes términos: "En efecto, según V. preveía, el artículo de 'Ínsula' sobre Gaudí ha producido revuelo. Sin contar con una réplica de Tharrats en 'Revista', han venido cartas y adhesiones de las gentes más insospechadas, como también rabiosas e insultantes recriminaciones. Con todo ello, Gaudí me gusta todavía menos que antes de escribir el artículo"35.

Sin detenerse mucho en ello, algunos temas del arte español del momento de cierta significación salen a relucir también en estas cartas. Así, varios comentarios de Gaya, siempre en diálogo con Millares, tienen que ver con Eugenio d'Ors y su Academia Breve de Crítica de Arte ${ }^{36}$. Si este asunto se menciona precisamente es porque el pintor canario participó (presentado por Pedro Mourlane Michelena) en la X Edición del Salón de los Once (1953), organizado por aquélla. La participación de Millares ${ }^{37}$, en la que tuvo una posición muy activa el escultor Ángel Ferrant, miembro de la Academia y amigo epistolar del pintor, se produce en la que será la última de estas colectivas, sin duda, una de la más abierta a la pintura de vanguardia. Se comprenderá esto si se tiene en cuenta que junto a Millares expusieron también sus obras, entre otros, Tàpies, Guinovart y Saura, en un marco expositivo que se había caracterizado, al menos en los años cuarenta, por la búsqueda de una modernidad atemperada en la que las claves de la tradición no estuvieran ausentes. No cabe duda del aprecio que Gaya sentía por el crítico catalán ${ }^{38}$; pero esto no impedía que viera la evolución tardía de la Academia dorsiana como un fenómeno decadente, pese a formar parte de ella, al menos nominalmente. Gaya tiene mucho cuidado con menospreciar la aportación del canario en este evento, pero lamenta las malas compañías que a su juicio acompañan la obra de éste: "Vi sus cuadros en el Salón de los Once, salón monstruosamente adulterado este año por la inclusión de dos o tres nulidades catalanas de las que seducen a don Eugenio d'Ors, ya en franco y lamentable declive. De aquí que mi brevísimo comentario en 'Ínsula' próxima sea tan breve e indignado. Por lo demás, don Eugenio no admite más voluntad que la suya. El poco favor que a ustedes les hace la compañía de Guinovart y Brotat, verdaderos analfabetos de la pintura, no es para dicho. Huelga decir que mi despectivo comentario del salón para

31 Gaya NuÑo, Juan A., "Dalí, epílogo de la bienal y de sí mismo", Ínsula, n. 75, marzo de 1952, p. 8. Gaya había escrito con anterioridad una monografía dedicada al pintor catalán (Barcelona, Omega, 1950), donde deja bien claro la negativa consideración que le merecía - por su inautenticidad- su obra posterior a 1936, argumento reiterado en el artículo de Ínsula.

32 Vid. Gaya NuÑo, Juan A., "Carta personal dirigida a Manolo Millares”, Barcelona, 19 de abril de 1952 (Archivo Elvireta Escobio, Cuenca).

33 GAYA NuÑo, Juan A., "En el centenario del Sr. Gaudí”, Ínsula, n. ${ }^{\circ}$ 81, septiembre de 1952.

34 A propósito de las reacciones que el artículo de Gaya provocó en el ámbito catalán, vid. MiralLEs, Francesc, "L'época de les avantguardes 1917-1970", en AA.VV., Història de l'art català, Edicions 62, Barcelona, 2005, v. VIII, p. 208.

35 Gaya NuÑo, Juan A., Carta personal dirigida a Manolo Millares, Barcelona, 22 de octubre de 1952 (Archivo Elvireta Escobio, Cuenca). Gaya reiterará sus valoraciones negativas sobre Gaudí en "Claves íntimas de la crítica...", art. cit., p. 178. Con todo, la posición del crítico soriano, que veía en la obra del catalán más extravagancia decorativa que verdadera arquitectura, no era compartida ni mucho menos por otros críticos de la época, como sucede, por ejemplo con Luis Felipe Vivanco, quien escribe en "Actualidad de Gaudí" (Revista, Barcelona, 24 de julio de 1952, p. 9) en términos muy elogiosos sobre la aportación del arquitecto modernista.

${ }^{36}$ Para seguir el recorrido histórico de la Academia Breve de Crítica de Arte sigue siendo válido -pese a su tono laudatorio- el libro de Sánchez Camargo, Manuel, Historia de la Academia Breve de la Crítica de Arte: Homenaje a Eugenio d'Ors, Madrid, 1963.

37 "Aborigen de Balos" (1952).

38 Vid. GAYA NuÑo, Juan A., "Mi don Eugenio d'Ors", Ínsula, n. ${ }^{\circ} 106,15$ de octubre de 1954, p. 1. 
nada se refiere a $V^{\prime \prime 39}$. En respuesta a esta carta, Millares lamentaba las opiniones tan desfavorables del crítico $^{40}$, a la vez que daba a entender que confiaba en su buen criterio a la hora de discernir sobre la calidad de los participantes en el evento en su artículo en Ínsula, con lo que se "cortarán las malas interpretaciones (sobre todo de mis paisanos, los isleños)"41, preocupación esta última que no dejará de ser recurrente en posteriores declaraciones del pintor o reflexiones epistolares, incluso cuando su imagen como artista adquiera un peso importante en el contexto del arte español de su época, esto es, en la década siguiente.

También se hace eco esta correspondencia de una noticia muy polémica en los primeros meses de 1952, cuyo sensacionalismo derivaba de la falsedad de la fuente que la difundía: las supuestas declaraciones de Picasso al escritor italiano Giovanni Papini, aparecidas en su Il libro nero $(1951)^{42}$. Estas declaraciones, en las que Picasso se manifiesta más bien como un artista lleno de cinismo, que considera caprichosa y extravagante su obra creada a partir del cubismo, una obra, además, que él entiende que está al servicio de una minoría social que satisface sus necesidades crematísticas, causaron un gran desconcierto en Millares, quien le pregunta, alarmado, a Gaya: “¿Qué sabe Vd. de todo eso? Siempre he creído a Picasso hombre sensato y espero no haya perdido la cabeza esta vez"43. La respuesta tranquilizadora del crítico va acompañada de una severa descalificación del autor italiano a la vez que desvela el oportunismo de aquéllos que ven en críticas de esta naturaleza la oportunidad para manifestar su alejamiento de la modernidad artística: "Pero, hombre, Millares, ¿cómo ha podido ser tan chiquillo como para creer en esta falsedad? Las declaraciones tales son imaginadas por el infecto católico Giovanni Papini, y nuestro gran Pablo jamás ha parlado con el malévolo escritor italiano. Ya sé que muchos periodiquillos las han publicado, tendenciosa e hipócritamente, como si fueran obra cierta del que es meta de nuestro orgullo. Pero él nada tiene que ver con el repugnante amaño"44.

Gaya Nuño siguió muy de cerca la evolución pictórica de Millares en estos años, como se puede ver en sus sucesivos comentarios a las exposiciones individuales del pintor canario en la Península. La primera de ellas (mayo de 1951), la muestra celebrada en la barcelonesa Galería de Arte Jardín, dentro del "III Ciclo Experimental de Arte Nuevo", suscita una opinión muy favorable por parte del crítico, que discrepa de la cortedad de miras con la que algunos han valorado esta obra, queriendo ver en ella solamente una familiaridad grande con el vibracionismo de Barradas y el constructivismo de Torres García ${ }^{45}$. 'La gente, 'espesa y municipal' -le escribe al pintor-, resbala imperturbable y no se da cuenta de nada. Nadie busca la verdadera belleza y, el que más, sólo se preocupa de relacionar lo de V. con lo de Torres García. En fin, el hecho es que su obra es excelente y yo le felicito de verdad”46.

39 Gaya NuÑo, Juan A., "Carta personal dirigida a Manolo Millares”, Barcelona, 5 de febrero de 1953 (Archivo Elvireta Escobio, Cuenca).

${ }^{40}$ Los comentarios tan negativos de Gaya Nuño hacia la obra de Guinovart contrastan con los expresados por el artista canario unos meses después, cuando le entreviste Cesáreo Rodríguez Aguilera en Revista (6-12 de agosto de 1953). En esta oportunidad, Millares habla de la pintura de Guinovart como admirable ejemplo de arte social con "aire y pulso de la pintura contemporánea".

${ }^{41}$ Millares, M., "Carta personal dirigida a Juan A. Gaya Nuño", Las Palmas, 17 de febrero de 1953 (Archivo Fundación Gaya Nuño, Soria).

${ }^{42}$ La primera traducción al castellano de este libro aparece en Buenos Aires (Ed. Mundo Moderno, 1952).

${ }^{43}$ Millares, M., "Carta personal dirigida a Juan A. Gaya Nuño", Las Palmas, 13 de junio de 1952 (Archivo Fundación Gaya Nuño, Soria).

${ }^{44}$ GaYa NuÑo, Juan A., "Carta personal dirigida a Manolo Millares", Barcelona, 20 de junio de 1952 (Archivo Elvireta Escobio, Cuenca).

${ }^{45}$ Resulta muy representativo de esta postura crítica el artículo de Juan Cortés en Destino (19 de mayo de 1951) sobre la exposición del artista canario.

${ }^{46}$ GaYa NuÑo, Juan A., "Carta personal dirigida a Manolo Millares”, Barcelona, 15 de mayo de 1951 (Archivo Elvireta Escobio, Cuenca).

Arch. esp. arte, LXXXIv, 334, ABRIL-JUNIO 2011, 107-124, ISSN: 0004-0428 
En junio de ese mismo año recibía Millares otra carta de Gaya en la que le comunicaba sus impresiones sobre la colectiva de "LADAC" celebrada en la galería Syra ${ }^{47}$, también en la ciudad condal. Lamentaba esta vez el crítico la inoportunidad de la fecha elegida para dar a conocer la obra del grupo grancanario, pues la temporada estaba ya casi cerrada, lo cual no quita para que felicite a Millares por lo expuesto, así como al resto de los participantes ${ }^{48}$.

De mayor interés resultan las declaraciones de ambos en torno a los cambios que introduce Millares en su pintura en 1953, cuando decide inclinarse por la figuración, abandonando su obra abstracta basada en la signografía aborigen. Aunque esta etapa suponga un paréntesis en la producción del pintor canario y vuelva pronto a una abstracción en la que la importancia de los materiales está más en sintonía con lo que será su obra posterior, da la impresión, a juzgar por las explicaciones que ofrece en esta ocasión, que corresponde a un giro de gran calado en su trabajo artístico ${ }^{49}$. De hecho, la producción mostrada en la galería Buchholz (enero de 1954) responde a esta orientación figurativa, en la que se reconoce alguna influencia de la pintura catalana, sobre todo de Guinovart. Al escribirle a Gaya en abril de 1953, le hace partícipe de estas novedades en su pintura en los siguientes términos: "Mi pintura está dando un cambio enorme. No le había dicho aún nada, porque quería asegurarme de lo que estaba haciendo. Con ella dejo lo absoluto, aunque lleva patente la experiencia abstracta" 50 . La respuesta del crítico es muy reveladora, pues las palabras de Millares parecen darle la oportunidad para clarificar su postura en torno a este tema. El debate sobre la abstracción en el arte español estaba entrando en una nueva fase muy polémica, como se constatará ese mismo año en el Congreso de Arte Abstracto de Santander, en el que participó, como ya adelantamos, el propio Gaya Nuño $0^{51}$. Las opiniones de Gaya sobre este tema se vierten también en algunos artículos de revistas ${ }^{52}$ en estos años. No puede decirse que la valoración que le merecía la abstracción fuera la propia de los críticos incondicionales, como se verá en España cuando arraigue el informalismo a finales de los cincuenta. Para Gaya, la abstracción había alcanzado un interés indiscutible como lenguaje decorativo (en el sentido más noble del término) y mural, pero no veía en la pintura de caballete resultados plásticos lo suficientemente consistentes. A lo sumo, reconocía la importancia que estas prácticas tenían como indagación plástica meramente experimental. Las palabras que le escribe a Millares a propósito de la citada carta no dejan mucho lugar a la duda: "Ciertamente, siempre he creído que lo abstracto era un callejón sin salida. Pero si se le encuentra salida, cual parece haber ocurrido en su caso, lo abstracto significa un adiestramiento que ofrece ilimitadas posibilidades" 53 .

Por lo demás, en estas cartas encontramos referencias explícitas al pasado carcelario del crítico, que sufrió la represión franquista como consecuencia de su pertenencia al vencido ejército republicano. Esta circunstancia, castigada por la justicia de entonces en concepto de "auxilio a la rebelión" (un auténtico sarcasmo histórico), le llevó a ser juzgado y condenado a una pena de

${ }^{47}$ En la exposición de Syra (16 al 30 de junio de 1951), cuyo catálogo contó con un texto de presentación de Eduardo Westerdahl, estuvieron presentes solamente Millares, Monzón, José Julio y Juan Ismael.

48 Cfr. GaYA NuÑo, Juan A., "Carta personal dirigida a Manolo Millares", Barcelona, 23 de junio de 1951 (Archivo Fundación Gaya Nuño, Soria).

49 Millares da a conocer estos cambios en la citada entrevista que concede a Césareo Rodríguez Aguilera en $R e$ vista de agosto de 1953, donde defiende un arte social "con aire y pulso de la pintura contemporánea".

${ }_{50}$ Millares, M., "Carta personal dirigida a Juan A. Gaya Nuño", Las Palmas, 2 de abril de 1953 (Archivo Fundación Gaya Nuño, Soria).

51 GAYA NuÑo, Juan A., "La pintura abstracta", en AA.VV., El arte abstracto y sus problemas, Ediciones de Cultura Hispánica, Madrid, pp. 189-213.

52 Vid. Gaya NuÑo, Juan A., "La pintura abstracta", Revista Española, n. ${ }^{\circ}$ 3, septiembre-octubre de 1953, pp. 307324, y "Las credenciales del arte abstracto", Ínsula, n. . 93, 15 de septiembre de 1953.

53 Gaya Nuño, Juan A., "Carta personal dirigida a Manolo Millares", Barcelona, 18 de abril de 1953 (Archivo Elvireta Escobio, Cuenca). 
cárcel de veinte años, luego conmutada a una de doce. Antes de conseguir la libertad condicional en 1943, Gaya pasó por varios penales, siendo precisamente uno de ellos el de Las Palmas de Gran Canaria, donde estuvo año y medio de su vida. En varias cartas dirigidas a Millares sale a colación este tema, debido a la necesidad que tiene el crítico de obtener el certificado de libertad definitiva, para lo cual eran necesarios unos trámites en la prisión de la capital grancanaria. En una misiva de abril de 1952, a propósito de esta penosa experiencia, dedica unas líneas evocadoras con las que describe el perfil humano de los dirigentes de la cárcel, líneas llenas de observación perspicaz, no exentas de sentido del humor: "Sabe Dios quiénes serán ahora; había un Director, el 'doble', a quién, después, he visto en Madrid; uno viejo y chiquitín, con bigotes enormes, se llamaba Don Tanis, y le llamábamos Don Stalin; había otro más, seco, consumido, con gafas; uno gordo, subdirector, con el que hablaba en latín... Bueno, apenas me acuerdo de aquella gente, contemporánea del gofio, y de los presos de Arucas y de Guía"54.

\section{Apuesta artística y promoción del arte contemporáneo en la correspondencia de Manolo Millares}

Entre otros rasgos, la actitud artística de Millares en estos años se distingue por la tenacidad con que aborda su dedicación a la pintura y la firmeza de sus convicciones en lo que se refiere a sus posibilidades como creador. En todo caso, había una falta de sintonía grande entre sus aspiraciones y un medio cultural pobre, generador de unas inercias contra las que el pintor levanta sus iniciativas a favor de la vanguardia plástica. "Cuando uno se encuentra desamparado -le escribía a Gaya en marzo de 1954- y a merced de una sociedad podrida y hostil, con todos los defectos añadidos de un insularismo cien por cien provinciano, es muy difícil amigo Gaya, sostenerse en pie y conservar la dignidad. Pero lo consigo, milagrosamente; lo sé, pero lo consigo. Continúo mi pintura, a pesar de las cosas que aquí se me hacen, porque de otra forma no podría ser, ni me interesaría ser" ${ }^{55}$. Había en estas palabras, desde luego, una gran determinación, a la que no era ajena la conciencia de estar cumpliendo en esos momentos una etapa en su vida artística, de cuya superación dependía la evolución posterior de su carrera en clave positiva, con todas las dificultades que ello implicaba. En este sentido se entienden las palabras que dirige al crítico unos años antes: "Estoy deseando siempre exponer, pero no por éxitos económicos, que nunca he conseguido, sino porque estoy en la edad en la que 'hay' que pasar un puerta por la que entran los que comienzan el penoso trabajo de la subida. Trato por todos los medios de llegar a ella antes de que se me cierre en las narices" $"$.

Como se puede confirmar por los comentarios anteriores, Millares no tenía en buena consideración el mundo artístico insular, con la excepción de aquéllos que con él formaron el grupo "LADAC", al que luego nos referiremos. Millares veía en el predominio de la pintura académica un fenómeno en clara connivencia con un público mal educado artísticamente y poco interesado por el arte contemporáneo. "El arte canario actual -le escribía a Gaya en marzo de 1952- (a Gran Canaria me refiero) se reduce a unos cuantos miembros de nuestro grupo LADAC. Los demás son pintores de señoras elegantes, paisajistas comerciales y dos o tres imitadores de ese artista

\footnotetext{
${ }^{54}$ GaYA NuÑo, Juan A., "Carta personal dirigida a Manolo Millares”, Barcelona, 19 de abril de 1952 (Archivo Elvireta Escobio, Cuenca).

${ }^{55}$ Millares, M., "Carta personal dirigida a Juan A. Gaya Nuño", Las Palmas, 6 de marzo de 1954 (Archivo Fundación Gaya Nuño, Soria).

${ }^{56}$ Millares, M., "Carta personal dirigida a Juan A. Gaya Nuño", Las Palmas, 4 de octubre de 1952 (Archivo Fundación Gaya Nuño, Soria).
}

Arch. esp. arte, LXXXIV, 334, ABRIL-JUNIO 2011, 107-124, ISSN: 0004-0428 


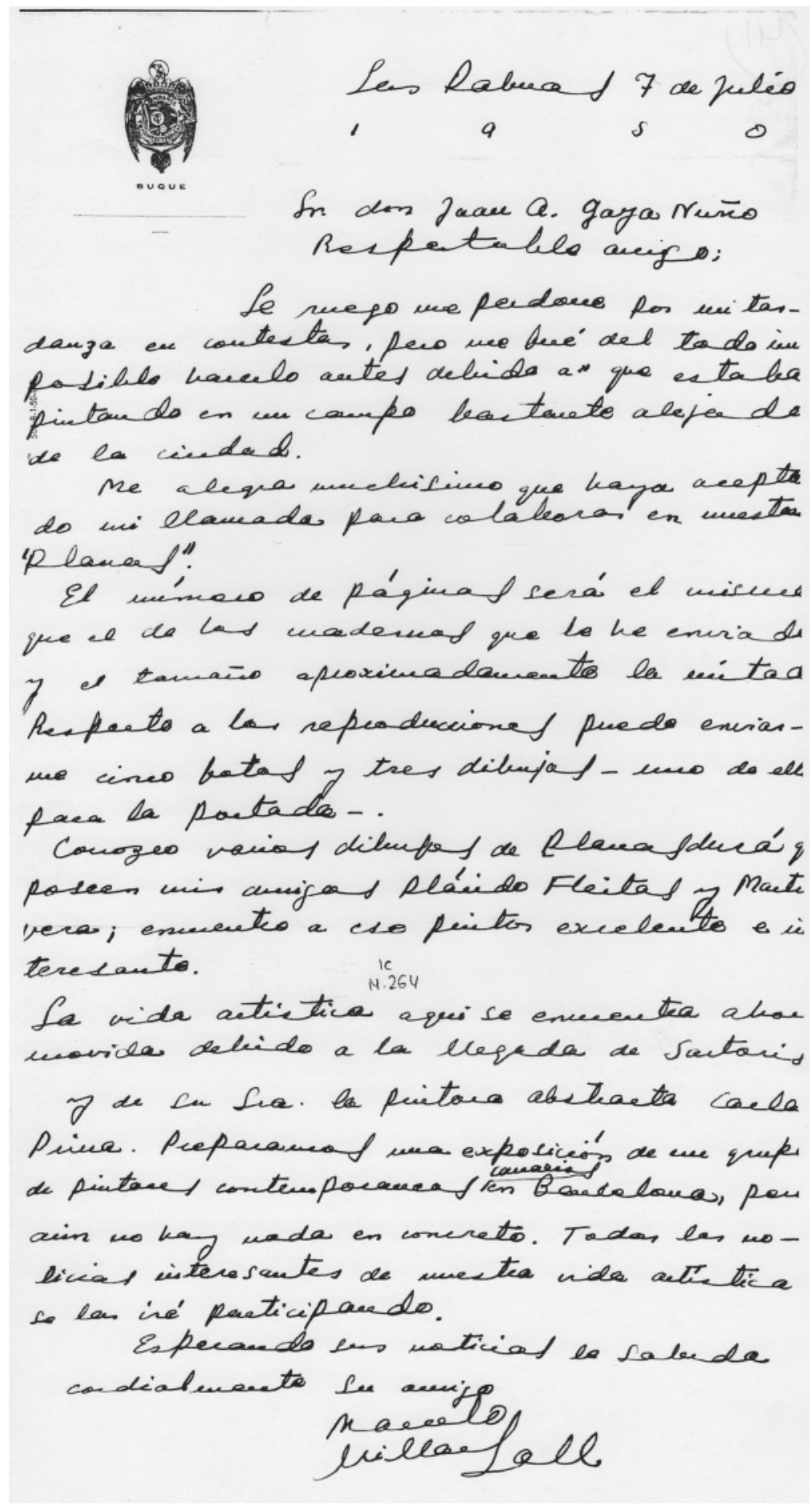

Fig. 2. Carta de Manolo Millares (7 de julio de 1950). 
funesto que se llamó Néstor. Todos estos juntos son los que reciben el apoyo incondicional de un público provinciano y estúpido, mientras vuelven sus miradas hostiles hacia nosotros" ${ }^{157}$. Ni qué decir tiene que de este ambiente poco propicio para el arte de innovación el pintor hacía partícipe también a gran parte de la crítica insular; por eso, no es de extrañar que, a propósito de la inauguración de una colectiva organizada por él en Las Palmas, le comente a Gaya, con indudable ironía: "todo fue muy bien y hasta la prensa nos ha dado ya dos espléndidas embestidas" $" 58$.

Puede sorprender la rotundidad con que Millares critica la pintura del simbolista Néstor, toda vez que no dejaba de ser una figura conocida a nivel nacional ${ }^{59}$, con una reputación innegable; pero como deja ver también en sus Memorias de infancia y juventud ${ }^{60}$, nada había en este artista que le resultara estimable, más allá de su habilidad como decorador. En cierta medida, los criterios que le servían para juzgar de manera desfavorable la pintura de Néstor podían ser válidos también para un artista más joven, como era el lanzaroteño César Manrique. Durante los años que recorren esta correspondencia, Manrique no solamente se ha situado en Madrid y desarrolla una labor importante como muralista, sino que también evoluciona en sus planteamientos pictóricos hacia un lenguaje propiamente abstracto ${ }^{61}$. Gaya Nuño, que sigue de cerca esta evolución, le recuerda a Millares en una carta de diciembre de 1954 que Manrique expone en ese momento en la madrileña Sala Clan, lo cual da pie a una respuesta que no ofrece lugar a dudas sobre la consideración que dicha pintura le merece: "En su pasada carta me hablaba Vd. de la exposición de Manrique. Estoy seguro, aunque no la he leído, que habrá tenido un éxito rotundo con sus obras en lo que respecta a crítica. Si le dejamos a Vd. aparte y a Sánchez Camargo, la crítica madrileña, que no entiende absolutamente nada de pintura contemporánea, habrá encontrado en César al verdadero y gran pintor moderno o, al menos, lo aceptará. Porque su pintura tiene la frivolidad suficiente y hasta ese 'chic' que puede producir el milagro. Este pintor es buen amigo mío y le acepto como gran decorador y colorista, pero la pintura va más allá en seriedad que su carácter" 62 . Habrá que esperar a los años sesenta para ver una mayor receptividad de Millares hacia la labor artística de Manrique, sobre todo por lo que se refiere a sus trabajos de tipo ambientalista en Lanzarote, una faceta artística que se escapa al ámbito cronológico de nuestro estudio.

Por otro lado, la combativa postura vital que muestra el pintor grancanario en sus cartas está detrás de la mayoría de las propuestas emprendidas por él durante este lustro; unas relacionadas con la actividad editorial y otras con la promoción del trabajo artístico, tanto suyo como del grupo que se aglutinó bajo las siglas de "LADAC". Cuando Millares inicia la correspondencia con Gaya, de los dos trabajos editoriales ya citados, el de "Planas de poesía" llevaba tiempo consolidado y el de las monografías de artistas "Los Arqueros" iniciaba ahora su andadura. En realidad, el motivo por el que Millares contacta por primera vez con Gaya Nuño no es otro que

\footnotetext{
57 Millares, M., Doc. cit.

${ }^{58}$ Millares, M., "Carta personal dirigida a Juan A. Gaya Nuño", Las Palmas, 2 de julio de 1952 (Archivo Fundación Gaya Nuño, Soria).

${ }^{59}$ La pintura de Néstor Martín Fernández de la Torre (1887-1938), el gran impulsor del tipismo canario, había gozado de considerable estima sobre todo en Barcelona, donde expuso frecuentemente y contó con la crítica elogiosa de Eugenio d'Ors.

${ }^{60}$ Cfr. Millares, M., Memorias de infancia y juventud, IVAM, Valencia, 1998, pp. 54-55.

${ }^{61}$ A propósito de la obra de Manrique durante este periodo, vid. los trabajos de Gómez Aguilera, Fernando y Carmona, Eugenio, César Manrique 1950-1957, Fundación César Manrique/La Caja de Canarias, 2006.

${ }^{62}$ Millares, M., "Carta personal dirigida a Juan A. Gaya Nuño", Las Palmas, 17 de enero de 1955 (Archivo Fundación Gaya Nuño, Soria). Opiniones muy parecidas a éstas se vierten también en algunas de las cartas que Millares escribe al pintor grancanario Felo Monzón en la segunda mitad de los cincuenta. Vid. Castro Morales, Federico y De la Nuez Santana, José Luis, "La correspondencia Monzón-Millares: radiografía de una época", en AA.VV., Felo Monzón. Retrospectiva, Las Palmas de G. Canaria, 1999, pp. 239-255.
}

Arch. esp. arte, LXXXIV, 334, ABRIL-JUNIO 2011, 107-124, ISSN: 0004-0428 
el de invitar a éste a escribir una monografía sobre un artista para esta colección, invitación que será aceptada por el crítico, que dedicará un estudio al pintor catalán Planasdurà, como ya se ha señalado. Mientras se prepara esta edición, en algunas cartas del crítico surgen algunos comentarios sobre la colección poética de "Planas de poesía", comentarios siempre elogiosos que demuestran un interés cierto por la misma, hasta el punto de que le pide al pintor más de un número atrasado. Por graves desavenencias con su hermano Agustín y el administrador, Rafael Roca, Manolo Millares había abandonado toda responsabilidad en la edición de estos cuadernos de poesía en febrero de 1951, coincidiendo con la aparición del número titulado El hombre de la pipa. El fondo del conflicto ${ }^{63}$ tenía que ver con una disparidad de criterios respecto a la función del arte como vehículo de expresión y la cuestión social. Aunque esta circunstancia -que el pintor vivió de manera especialmente intensa- no aparece reflejada en esta correspondencia, si se señalan brevemente las razones de tipo político que llevaron al cierre de esta colección. "Seguramente Ud. ignorará -le escribe al crítico en noviembre de 1951- todos los líos en los que aquí nos hemos visto envueltos. Sospecha de complot comunista. Nuestra colección Planas de Poesía suspendida, mis hermanos en la cárcel y muchísimas cosas más que me tendrían mucho tiempo escribiéndole" $"$. Todavía en abril del año siguiente hay un nuevo recuerdo para esta colección poética y su penosa historia final, cuando el pintor le recuerda a Gaya cómo, a consecuencia de los registros, la policía se había llevado casi todos los números de la colección ${ }^{65}$.

Frecuentemente encontramos en las cartas escritas por el pintor alusiones a "LADAC", aunque ese nombre no aparezca hasta 1951 y en un principio Millares emplee el de "Planas de Arte" para identificar a este grupo de artistas, denominación que rápidamente asociamos con la colección "Planas de poesía". Seguramente influyó en el cambio de nombre la ruptura de relaciones que se llevó a cabo entre los responsables de estas ediciones poéticas, como acabamos de ver. Los comentarios que podemos entresacar sobre el grupo "Los Arqueros del Arte Contemporáneo" en esta correspondencia tienen más que ver con determinadas observaciones descalificadoras hechas por parte del pintor que con lo que sería la pura información divulgativa de su labor. El pintor no llevó muy bien el desdén con el que la crítica catalana trató a "LADAC" cuando éste expuso en la sala Syra de Barcelona (junio de 1951) ${ }^{66}$. Millares entendía por aquellas fechas que Barcelona "es sólo catalana y terriblemente hostil a cualquier forastero" ${ }^{67}$, queriendo con ello también marcar las diferencias con respecto a Madrid e identificándose de paso con las opiniones a este respecto de su interlocutor epistolar, muy poco proclive a valorar de manera positiva el ambiente artístico catalán, como vimos. A estas alturas de la historia de "LADAC", el artista canario se mostraba bastante decepcionado con el desinterés de algunos de los integrantes del grupo, pues, como señala en la misma carta, "muchos miembros de LADAC no se ocupan ya de coger los pinceles todas las veces que debieran"68. Todas estas impresiones dejaban ver la existencia de discrepancias muy grandes en las formas de entender el trabajo artístico entre ellos,

63 A propósito de este asunto, vid. De la Nuez Santana, José Luis, “'Planas de poesía' y la polémica sobre la abstracción”, en La abstracción pictórica en Canarias, Cabildo Insular de G. Canaria, Las Palmas de G. Canaria, 1995, pp. 315-323.

${ }^{64}$ Millares, M., "Carta personal dirigida a Juan A. Gaya Nuño", Las Palmas, 26 de noviembre de 1951 (Archivo Fundación Gaya Nuño, Soria).

${ }^{65}$ Cfr. Millares, M., "Carta personal dirigida a Juan A. Gaya Nuño", Las Palmas, 30 de abril de 1952 (Archivo Fundación Gaya Nuño, Soria).

${ }^{66}$ Entre estas críticas desfavorables están las de Alberto del Castillo ("El grupo 'LADAC' de Gran Canaria en Syra", Diario de Barcelona, Barcelona, 20 de junio de 1951, p. 13) y Juan Cortés ("LADAC", Destino, n. ${ }^{\circ}$ 724, Barcelona, 23 de junio de 1951, p. 21).

${ }^{67}$ Millares, M., "Carta personal dirigida a Juan A. Gaya Nuño", Las Palmas, 18 de febrero de 1952 (Archivo Fundación Gaya Nuño, Soria).

68 Ibidem. 
sobre todo entre los más jóvenes y aquéllos que, como Juan Ismael y Felo Monzón representaban la facción más veterana, ligada a la historia de la Escuela "Luján Pérez". Con el último citado fue Millares nada condescendiente a propósito de la última exposición del grupo, una colectiva de 1952, celebrada en el Museo Canario de Las Palmas. Aunque sin citarlo expresamente, en la carta que escribe a Gaya en julio de 1952 le hace ver a éste su descontento por la forma de actuar de este pintor en los siguientes términos: "¿Qué puede pensarse de un pintor que hace exactamente un año y un mes que no coge los pinceles, a quien venimos pidiéndole desde hace dos meses que haga alguna cosa para nuestra exposición, y que no habiendo hecho nada, hayamos tenido que colgar unos dibujos suyos que poseían los amigos y que llega después de inaugurada la exposición y los descuelga estúpidamente?"69. Frente a la evidente laxitud de modos como los descritos, Millares, por el contrario, mostraba su disposición firme a luchar por una apuesta artística en la que concentraba todas sus energías. No cabía, en este sentido, administrar los tiempos del arte en función de otros intereses ajenos a éste, como le sucedía a Monzón, cuyas circunstancias personales eran bien distintas, bien es cierto.

Queda dicho que las relaciones epistolares de Manolo Millares con la crítica española de estos años son decisivas para entender el grado de implicación del artista canario en el contexto de la pintura vanguardista española. Resulta indiscutible su identificación con los planteamientos de algunos críticos del momento. De hecho, en las cartas que son objeto de estudio se revela la estima, bastante natural y auténtica, que le merecía el juicio formado de Gaya Nuño; sin embargo, la opinión que el pintor canario mantenía sobre otros representantes de la crítica madrileña dejaba mucho que desear. La carta que le escribe al soriano en febrero de 1954, a propósito de su exposición en la galería Buchholz, es un documento muy revelador de sus prevenciones hacia lo que él entiende es una postura intelectual en la que lo que tiende a ser dominante es el desconocimiento de la realidad artística contemporánea. Por eso, "ese "no saber' exactamente lo que está operándose en el arte, hace que estos señores se muestren inseguros, poniendo siempre en sus críticas una vela a Dios y otra al diablo, por lo que pueda pasar. De ahí que nunca se clareen ni sepan adoptar una postura clarividente y rotunda"70. Con la intención de ser más claro en su diagnóstico, Millares cita dos ejemplos que pueden ilustrar, con los comentarios que hacen sobre la citada exposición, esta orientación de la crítica española contemporánea: Figuerola Ferretti, del periódico Arriba, y Castro Arines, crítico habitual en esta época del periódico Informaciones. Al primero le reprocha el "temor a equivocarse y perder el bien ganado prestigio", y esa tendencia a demostrar una necesaria erudición, trayendo a colación nombres de artistas famosos, como Picasso, Klee y Chagal, lo "que sólo consigue reforzar la creencia de su propia ignorancia" "71. A Castro Arines, Millares le critica la utilización equivocada que hace de la expresión "negrismo" -empleada por el propio Gaya Nuño en el catálogo de Buchholz-, estableciendo relaciones absolutamente improcedentes con la pintura picassiana ${ }^{72}$.

No faltan tampoco en las cartas escritas por Millares comentarios sobre su propia obra. Son, en cualquier caso, observaciones breves que sirven para señalar la diversidad de propuestas de su pintura a lo largo de unos años en los que el artista canario no ha alcanzado todavía la definición de un estilo pictórico que podamos considerar definitivo, algo que no se verá hasta la segunda mitad de los cincuenta. A sus pictografías se refiere someramente al principio de esta correspondencia, cuando le señala al crítico que sus últimas pinturas tienen "ciertos caracteres autóctonos que les apartan algo de las almas peninsulares", aunque tanto "Sartoris como Wester-

\footnotetext{
69 Millares, M., Doc. cit.

70 Millares, M., Doc. cit.

71 Ibid.

72 Cfr. Ibid.
} 
dahl quedaron bastante satisfechos"73 con estos resultados. Esta afirmación última se vería refrendada por el artículo, ya aludido, que el arquitecto italiano dedicó a esta obra en Ínsula. Siguiendo precisamente una terminología empleada por Sartoris y Westerdahl en los primeros cincuenta para denominar a la abstracción, frecuentemente, Millares incluía sus pictografías dentro del absolutismo pictórico. Dos años después le explica a Gaya que trabaja en un tipo de obras ("Retablo Africano", "Candelario Plástico") que suponen una "unión entre mi constructivismo anterior y mis pictografías últimas" ${ }^{\prime 74}$, confirmando de esta manera la pluralidad de soluciones que su obra aporta durante estos años. De abril de 1953 es la carta ya estudiada en la que Millares anuncia el abandono de la abstracción y su apuesta por una figuración renovada, aunque, como ya se puntualizó, este momento no dejó de ser un paréntesis dentro de la orientación general de su pintura en estos años. La cuestión de la abstracción está presente también en cartas posteriores, sobre todo en la escrita en marzo de 1955, cuando el pintor le hace ver al crítico cómo algunos han hecho una lectura "antiabstractista" de su reciente libro La Pintura ${ }^{75}$, viendo en la ausencia de representantes de la abstracción en el libro un manifiesto desprecio hacia esa tendencia plástica. Para Millares, la abstracción era lo suficientemente reciente como para pretender un puesto consolidado en las visiones históricas de la pintura española contemporánea: "Yo, por mi parte, no vi ninguna intención rara en los nombres escogidos por Vd., pues la pintura abstracta española es aún demasiado joven para que sus frutos puedan servir de paradigma y creo que Vd. (que jamás ha tenido nada en contra de esta escuela) ha seleccionado bien los nombres" 76 . Todavía una referencia más, en mayo del mismo año, confirma sus preferencias por la abstracción, con un matiz importante al hablar de nuevas obras suyas, que son "cuadros tratados con una técnica bastante personal (fragmentos de cerámica aborigen, tierra, polvos de temple, arena, óleos y otras cosas)" "77; algo que no hacía sino corroborar que antes de su partida a la capital española ya había iniciado su inclinación hacia el informalismo matérico, que definirá toda su producción posterior.

Como se ha podido ver en detalles ya estudiados de esta correspondencia, aparece recogida también en ella toda la febril actividad expositiva desplegada por el pintor canario en este periodo. Decididamente, fue este interés en exponer con asiduidad lo que hizo de Millares un artista conocido en suelo peninsular antes de que fijara su residencia en Madrid, y todo ello a pesar de los múltiples problemas que la preparación de estas muestras traían consigo, no solamente por el costo que ello implicaba, sino también, dado el peculiar régimen económico de islas, por las trabas aduaneras que había que superar cada vez que se sacaban las obras fuera del archipiélago. Valgan como ejemplos de todas estas dificultades las distintas tentativas para exponer en la galería Clan de Madrid, después de su primera individual en esta sala, celebrada en noviembre de 1951. La primera de estas tentativas fue abortada por las gravosas condiciones económicas que

${ }^{73}$ Millares, M., “Carta personal dirigida a Juan A. Gaya Nuño”, Las Palmas, 30 de julio de 1953 (Archivo Fundación Gaya Nuño, Soria).

${ }^{74}$ Millares, M., "Carta personal dirigida a Juan A. Gaya Nuño", Las Palmas, 6 de marzo de 1952 (Archivo Fundación Gaya Nuño, Soria).

75 Gaya Nuño, Juan A., La Pintura, op. cit. El libro es propiamente una introducción a la historia de la pintura vanguardista, donde se ponen de manifiesto nuevamente los recelos de Gaya hacia el surrealismo. No puede entenderse, en todo caso, como un texto en contra de la abstracción, pues ésta es considerada como una legítima forma de expresión con espacio propio en el mundo artístico contemporáneo. Otra cosa es la valoración que la pintura abstracta española le merece al crítico en ese momento, pues después de asegurar que “...el interés por lo abstracto es muy limitado en España”, no cita ningún nombre relacionado con esta tendencia (p. 157).

${ }^{76}$ Millares, M., "Carta personal dirigida a Juan A. Gaya Nuño", Las Palmas, 25 de marzo de 1955 (Archivo Fundación Gaya Nuño, Soria).

77 Millares, M., "Carta personal dirigida a Juan A. Gaya Nuño", Las Palmas, 27 de mayo de 1955 (Archivo Fundación Gaya Nuño, Soria). 
el galerista, Tomás Seral, comunicó al pintor. "Tenía el proyecto -escribe a Gaya- (creo que se lo anuncié en mi pasada carta) de exponer en 'Clan' para abril del próximo año. Sin embargo, acabo de romper mi compromiso con dicha galería, por no convenirme su actual actitud. Me pide 2.000 pesetas sólo por la galería y catálogos (El año pasado me puso marcos y notas de prensa) y no estoy en condiciones de gastar mucho dinero"78. Además, por lo que cuenta el artista canario, había también ciertas reticencias hacia su obra abstracta por parte de Seral, que no veía en ella una atención crítica destacable ${ }^{79}$. Más complicada parece la historia de la exposición que preparó para octubre de 1954 en la misma galería, ahora dirigida por José Antonio Llardent; una exposición que nunca se llegó a realizar en tal fecha ${ }^{80}$ debido a un cúmulo de circunstancias adversas que aparecen comentadas por el pintor en sucesivas cartas. Como era habitual en estas exposiciones preparadas desde Canarias, el artista enviaba la obra con la esperanza de que el resto de los trámites que permitían finalmente colgar las pinturas en la sala se desarrollaran en los tiempos convenidos, pero sin estar él presente en el control de todo ello. A todo esto habría que unir que la desinformación era muy grande. El 19 de octubre le escribe, confiado, a Gaya: "Supongo, aunque no he recibido noticia alguna, que ya se habrá inaugurado en 'Clan' mi exposición de óleos. ¿La vio Vd. ya? Sabe que su opinión me interesa muchísimo y espero conocer su criterio" " 1 . Lo cierto es que esa suposición no tenía mucho fundamento, como el propio artista confirma en la carta siguiente enviada al crítico: "Mi exposición en 'Clan', por las pocas noticias que me han llegado, no ha podido hacerse debido a la detención de mi obra en la aduana de Barajas; jun desastre! ¡Yo, que tenía tanto interés en esa exposición de Madrid!"\$2. Incluso hay una carta más sobre este tema en la que el artista transmite su desánimo por el poco interés que el galerista ha puesto en resolver el problema. En tono muy agrio, escribe: "¿Sabe Vd. que Llardent, director de Clan, ha resultado ser un sinvergüenza? Hace dos meses que no me escribe una sola palabra (a pesar de mis cuatro cartas y mi telegrama). He tenido una conferencia telefónica con él y me ha engañado con no sé que certificado de origen. La verdad es que, según me comunica la compañía de 'Aviación y Comercio' y la Aduana madrileña, Llardent pudo sacar los cuadros (y puede) con solo pagar unos derechos (muy poco dinero: diez pesetas por cada cuadro), pero ni ha querido, ni me ha pedido a mí el dinero, ni nada"83. Hasta el propio Gaya acabó mediando en el asunto e interesándose por el paradero de los cuadros que iban a ser expuestos en la sala madrileña. El crítico explicaba el embrollo de los cuadros retenidos en la aduana de tal forma que liberaba de responsabilidad al galerista, pues, como puntualizaba en una misiva de diciembre de ese año, "quizás la culpa no sea ni de Clan ni de Vd., sino de los tentáculos de la

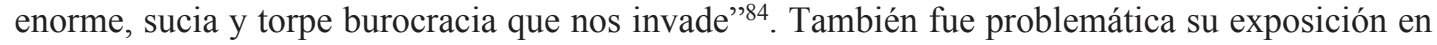
la madrileña galería Buchholz, inaugurada finalmente en enero de 1954, después de superar las reticencias de la galerista, que hicieron inviable la posibilidad de que la muestra se abriese en

\footnotetext{
${ }^{78}$ Millares, M., "Carta personal dirigida a Juan A. Gaya Nuño”, Las Palmas, 5 de diciembre de 1952 (Archivo Fundación Gaya Nuño, Soria).

${ }^{79}$ Cfr. Ibidem.

80 Ya en 1955, Millares expondrá en Clan en dos ocasiones. La primera de ellas se inaugurará el 16 de febrero, aunque se trata de una muestra restringida a cuatro obras. Más importante será su exposición inaugurada el 10 de noviembre, cuando ya el pintor vive en Madrid. En esa ocasión, Vicente Marrero escribirá el texto del catálogo.

${ }^{81}$ Millares, M., "Carta personal dirigida a Juan A. Gaya Nuño", Las Palmas, 19 de octubre de 1954 (Archivo Fundación Gaya Nuño, Soria).

${ }^{82}$ Millares, M., "Carta personal dirigida a Juan A. Gaya Nuño", Las Palmas, 4 de noviembre de 1954 (Archivo Fundación Gaya Nuño, Soria).

${ }^{83}$ Millares, M., "Carta personal dirigida a Juan A. Gaya Nuño", Las Palmas, 1 de diciembre de 1954 (Archivo Fundación Gaya Nuño, Soria).

${ }^{84}$ Gaya Nuño, Juan A., "Carta personal dirigida a Manolo Millares", Barcelona, 14 de diciembre de 1954 (Archivo Elvireta Escobio, Cuenca).
} 
noviembre del año anterior y el artista pudiera estar presente en esa ocasión. Como sucedió con todo el asunto en torno a Clan, el artista se veía nuevamente perjudicado en gran medida por el hecho de vivir en las islas, con todo lo que ello suponía de impotencia a la hora de tomar decisiones y controlar aquellas gestiones que son vitales para la difusión de la obra de un creador que necesita imperiosamente darse a conocer. Resulta más que esclarecedor a este respecto lo que le escribe a Gaya el 16 de enero de 1954, cuando ya la exposición se ha inaugurado: "Ayer recibí varios catálogos de mi exposición en 'Buchholz' y me enteré que se abrió el día once. ¡Y aún no sé absolutamente nada sobre ella! ¿Fue Vd. a la inauguración? ¿Ha gustado mi obra?" 85.

Todo este conjunto de dificultades derivadas de su residencia isleña y la buena impresión que le causó el mundo artístico madrileño en su viaje realizado en 1953 llevaron a Manolo Millares a la convicción de que lo mejor para su carrera artística era dejar las islas e instalarse en la capital del país, pese a lo que todo ello suponía de riesgo personal, teniendo en cuenta las pésimas condiciones económicas de partida. En la última carta que le escribe el pintor al crítico menciona a varios de los que partirían con él a Madrid, como eran el escultor Martín Chirino y el poeta Manolo Padorno, a la vez que incorpora, a modo de despedida, una reflexión muy reveladora del momento decisivo que vive el artista canario: "Espero que todo me vaya bien esta vez. Necesito -y ¿quién no? - un poco de comprensión y especialmente ahora, en vísperas de un paso tan duro y definitivo como el que voy a dar" $" 86$.

Fecha de recepción: 10-X-2009

Fecha de aceptación: 14-I-2010

\footnotetext{
${ }^{85}$ Millares, M., “Carta personal dirigida a Juan A. Gaya Nuño”, Las Palmas, 16 de enero de 1954 (Archivo Fundación Gaya Nuño, Soria).

${ }^{86}$ Millares, M., "Carta personal dirigida a Juan A. Gaya Nuño", Las Palmas, 22 de julio de 1955 (Archivo Fundación Gaya Nuño, Soria).
} 